\title{
Modeling aspects concerning the axial behavior of $R C$ columns
}

\author{
H. O. Koksal ${ }^{1}$, T. Turgay ${ }^{2}$, C. Karakoç ${ }^{3}$ \& S. Ayçenk ${ }^{4}$ \\ ${ }^{1}$ Construction Technology Program, Çanakkale Onsekiz Mart University, \\ Turkey \\ ${ }^{2}$ Faculty of Engineering and Architecture, Abant İzet Baysal University, \\ Bolu, Turkey \\ ${ }^{3}$ Civil Engineering Department, Boğaziçi University, Turkey \\ ${ }^{4}$ M.S. Student, Civil Engineering Faculty, Yıldız Technical University, \\ Turkey
}

\begin{abstract}
This paper is concerned with the axial behavior of the RC columns. Stress-strain relationships of experimentally tested $\mathrm{RC}$ columns under concentric loading are compared with the predictions of the Koksal model. Moment-curvature analyses of RC sections are also performed employing the same model in a self-developed moment-curvature program for confined concrete. Results are compared with the output of EXTRACT which uses the Mander concrete model.
\end{abstract}

Keywords: confinement, reinforced concrete columns, concentric loading, stress-strain relations.

\section{Introduction}

Confining pressure on RC columns increases the concrete strength. Transverse reinforcements such as steel stirrups, FRP wraps, and steel jackets create a triaxial compressive stress state producing confinement action around the concrete core. Extensive research on the improvement of concrete confinement has been carried out since the pioneering study of Richart et al. [1]. The constitutive model for confined concrete plays an important role on the accuracy of the moment-curvature curves to perform a reliable pushover analysis of RC frames. There are some frequently cited models (Hognestad [2], Kent and Park [3], Sheikh and Uzumeri [4], Mander et al. [5], Saatcioglu and Razvi [6]) to predict 
the peak stress or the stress-strain curve of confined concrete. Köksal has also proposed a failure criterion for concrete under tri-axial compression stress state [7]. In this paper, four square RC columns tested in Yildız Technical University (Turgay [8], Köksal et al. [9]) are evaluated implementing Koksal model. The flexural behavior of the columns is also simulated and their moment-curvature relations corresponding to different axial load levels are obtained using the same model. Moment-curvature curves are compared with the outputs of EXTRACT.

\section{Experimental study}

The square specimens in the test program have $200 \times 200 \mathrm{~mm}$ cross-section dimensions and $1000 \mathrm{~mm}$ height. The columns were tested in the structural laboratory of Yildız Technical University [8]. Figure 1 shows the details of test setup and instrumentation for the two specimens.

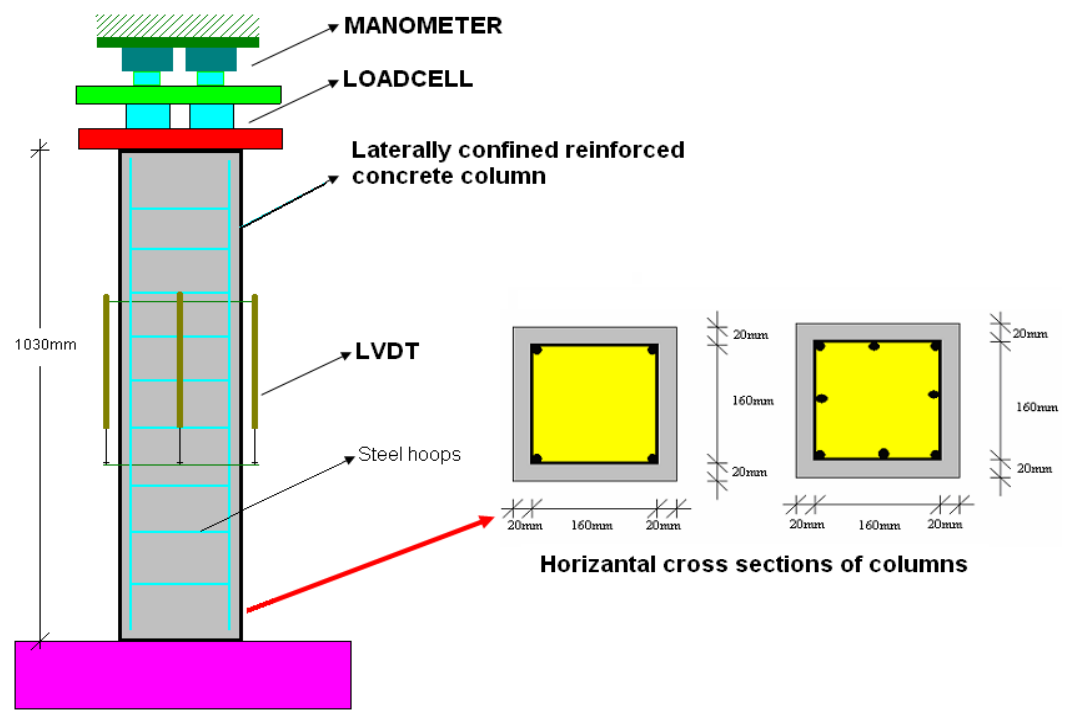

Figure 1: $\quad$ Test setup and details of test specimens C1L4S8 and C1L8S8 [8].

The experimental study was limited to one type of concrete mix design typically. $\mathrm{C} 1$ type columns are tested at 30 days. All longitudinal bars are $10 \mathrm{~mm}$ in diameter and L4 and L8 shows the number of the bars in the cross-section of a column. The tie spacing is $100 \mathrm{~mm}$ and the $\mathrm{S} 8$ represents diameter of stirrups. For measurement of axial strains, four linear variable displacement transducers (LVDTs) are placed over the central $400 \mathrm{~mm}$ gage length at each side of a column in a similar way used to assess any eccentricity of the applied load as recommended in the study of Shrive et al. [10]. Although the LVDT readings were provided very close to each other, next to the maximum axial load there can be a significant variation between the minimum and maximum values of shortening reaching very high values [9]. Figure 2 shows the axial load-axial 
shortening curve for C1L8S8 for which almost perfectly homogeneous strains were obtained. However, for other columns the differences between LVDT readings are somewhat greater indicating a localized damage zone at one specific region of the specimen.

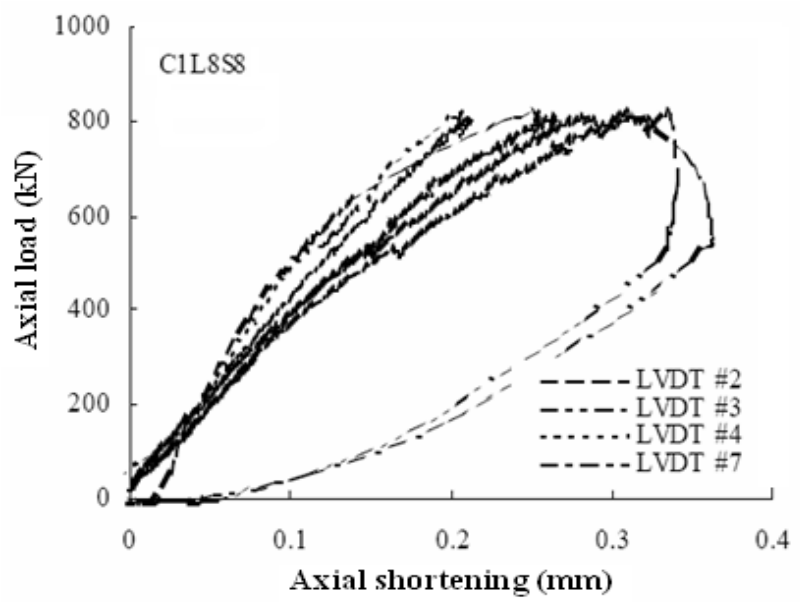

Figure 2: Four separate LVDT readings of axial load-shortening curves for C1L8S8 [9].

\section{Simulation of flexural behavior and moment curvature relations}

The limit state design procedure of reinforced concrete elements has undergone major revision by most of the international codes in harmony with the performance-based design engineering approach. In this approach, momentcurvature behavior of flexural members is needed to define the deflection demand and to simulate the behavior of the reinforced concrete members under lateral loads such as earthquake actions. Moment-curvature plots readily illustrate stiffness, strength, and cross-sectional ductility, and allow the calculation of deflections after materials become nonlinear. In a flexural member the shear reinforcement or any other confinement mechanism applies pressure to the concrete in the compression zone and affects energy dissipation capacity directly. Therefore, to predict the moment-curvature behavior of a flexural member, the stress-strain behavior of confined concrete under axial compression is vital. With the development of performance-based design methods, there is an increasing need for simplified but reliable analytical models capable of predicting the flexural behavior of reinforced concrete members. The flexural behavior of reinforced confined concrete sections is introduced by Koksal model [7]. The failure criterion proposed by Koksal is given as:

$$
f=1.1317 \xi^{0.7645}+\rho-\sqrt{2} k\left(\sigma_{1}, \sigma_{2}, \sigma_{3}\right)=0
$$


where $k=k\left(f_{l}, f_{c}^{\prime}\right), \rho$ and $\xi$ are deviatoric and hydrostatic lengths, respectively. In this equation $\mathrm{k}$, as a function of the lateral confinement pressure, $f_{l}$, and the cylinder compressive strength of concrete, $f_{c}^{\prime}$ can be expressed as [7] :

$$
k=\left(4.07 \frac{f_{l}}{f_{c}^{\prime}}-0.89\left(\frac{f_{l}}{f_{c}^{\prime}}\right)^{2}+0.807\right) f_{c}^{\prime}
$$

The theoretical confining pressure, $f_{l}$, can be found in usual way as [11] :

$$
f_{l, x}=k_{e} \rho_{s x} f_{y h} \quad \text { or } \quad f_{l, y}=k_{e} \rho_{s y} f_{y h}
$$

In this relation, $\rho_{s x}$ and $\rho_{s y}$ are the confinement proportion both $x$ and $y$ direction respectively, $k_{e}$ is the confinement effectiveness coefficient, and $f_{y h}$ is the yield strength of transverse reinforcing steel. The Saenz's equation [12] is adopted for describing the monotonic stress-strain relationship for confined concrete:

$$
\sigma_{1}=\frac{\varepsilon_{1} E_{0}}{1+\left(\frac{E_{0}}{E_{s}}-2\right)\left(\frac{\varepsilon_{1}}{\varepsilon_{c c}}\right)+\left(\frac{\varepsilon_{1}}{\varepsilon_{c c}}\right)^{2}}
$$

where $\sigma_{1}$ and $\varepsilon_{1}$ are axial compressive stress and strain of concrete, respectively; $E_{0}$ is the initial tangent modulus of elasticity in MPa and can be calculated as $E_{0}=4750 \sqrt{f_{c o}^{\prime}} ; E_{s}$ is the secant modulus at the point of maximum compressive stress $f_{c c}^{\prime}$ which can be determined using Equation 1. The strain $\varepsilon_{c c}$ corresponding to the maximum compressive stress $f_{c c}^{\prime}$ can be found employing the recommended relations of Richart et al. [1] :

$$
\varepsilon_{c c}=\varepsilon_{c}^{\prime}\left(1+k_{2} \frac{f_{l}}{f_{c}^{\prime}}\right)
$$

where $\varepsilon_{c}^{\prime}$ is the peak strain at the strength of plain concrete cylinders. In this equation, $k_{2}$ is taken as $5 k_{1}$.

Figure 4 aims to compare experimental axial stress-strain curves of the four column specimens with those predicted from Eqs (1)-(4).

In this study, a simple program is written in FORTRAN to produce momentcurvature plots for confined column section under bending and axial compression. The cross section is divided into $1 \mathrm{~mm}$ thickness slices. For a given depth of natural axis, the strain at the extreme slice in compression is found by iterative procedure. For each slices, the stress and strain are calculated using force equilibrium and compatibility requirements respectively. Stress acting on the core concrete (cover concrete is neglected) calculated using Koksal's model. Koksal's model has also been utilized through the 3D finite element analysis of $\mathrm{RC}$ and FRP-confined concrete columns [11, 13] successively. Figure 3(a) 
demonstrates the typical axial stress-strain curves recommended by Saenz for a concrete member [12]. Finite concrete forces for unconfined and confined core of each slice are found by multiplying stress by corresponding areas. Stress at the reinforcement bars is found by entering a simple bi-linear stress-strain curve in Figure 3(b) with the strain value found from compatibility requirements at each load level. Finite forces on steel can be found by multiplying stress by the area of the reinforcement.

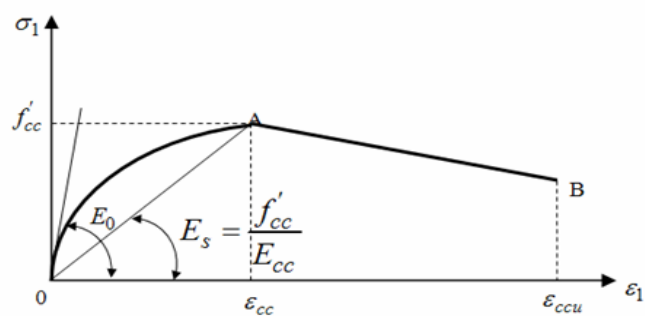

(a)

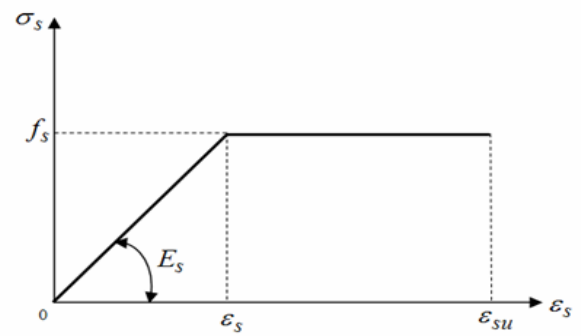

(b)

Figure 3: (a) Saenz curve for uniaxial behavior of concrete; (b) stress-strain relation for steel.
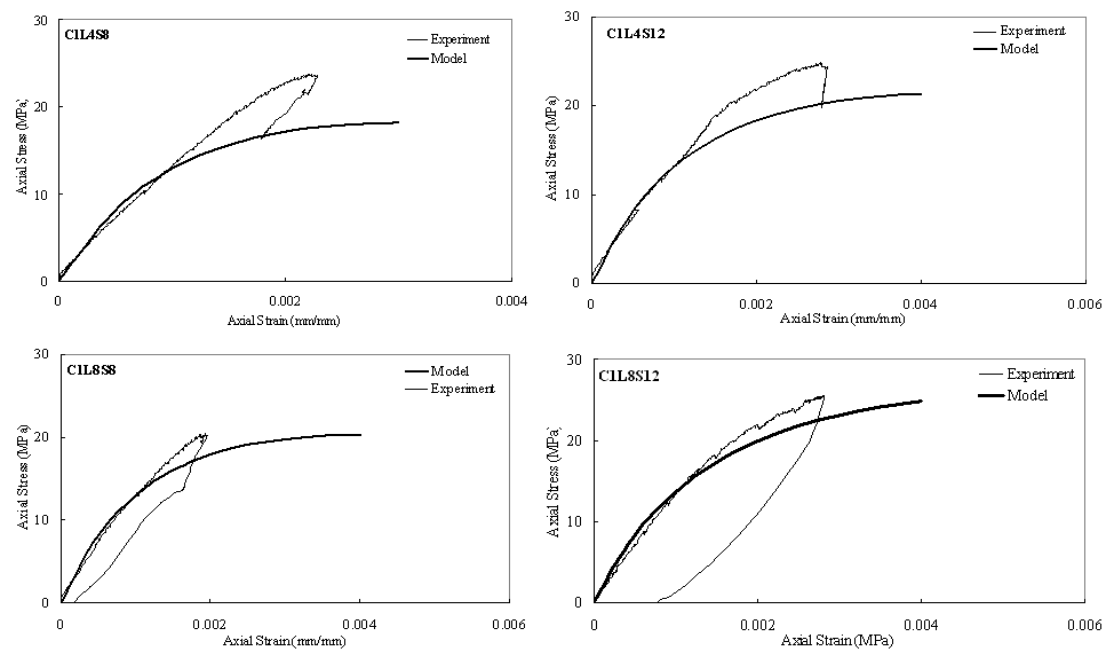

Figure 4: $\quad$ Experimental and predicted stress-strain curves for the specimens. 
Figure 5 show the moment-curvature relations for C1L4S8 and C1L8S8 at various load levels. Increasing the axial load from $200 \mathrm{kN}$ to $400 \mathrm{kN}$ always results an increase in the moment carrying capacity. But when a load near to the axial load capacity is considered, moment carrying capacity does not increase any more. Also decrease in the curvature is very obvious when the axial load increases as expected.
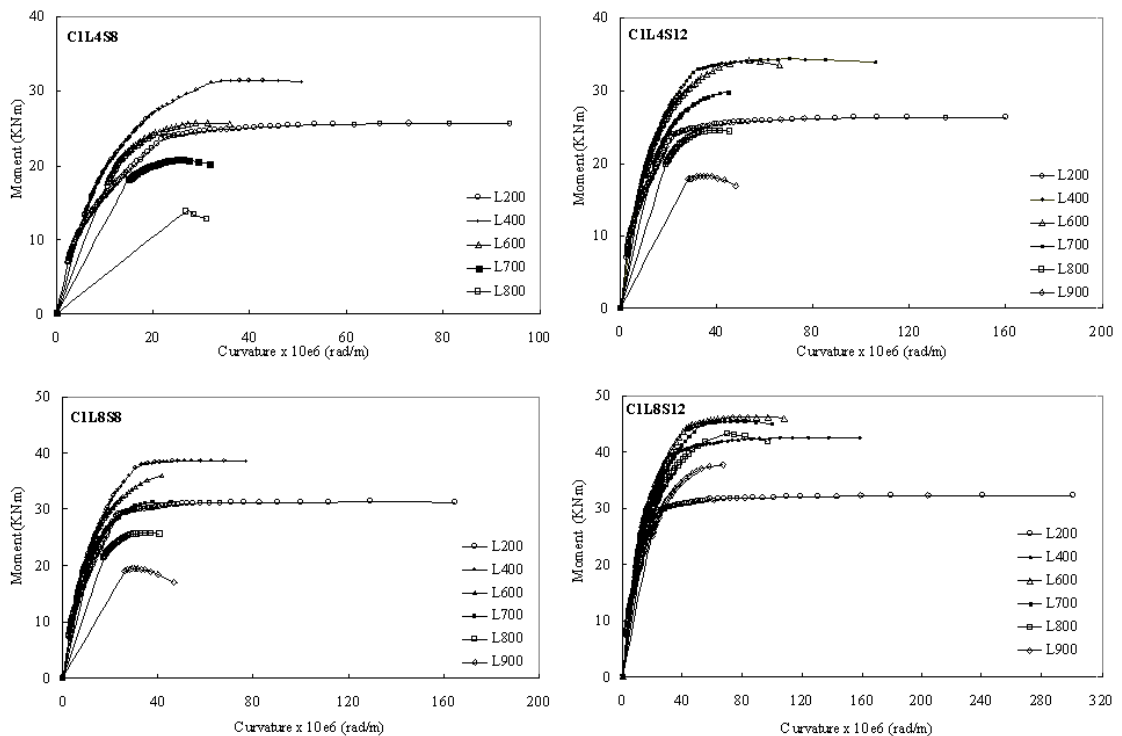

Figure 5: Moment-curvature diagrams for the four columns at various axial load levels.

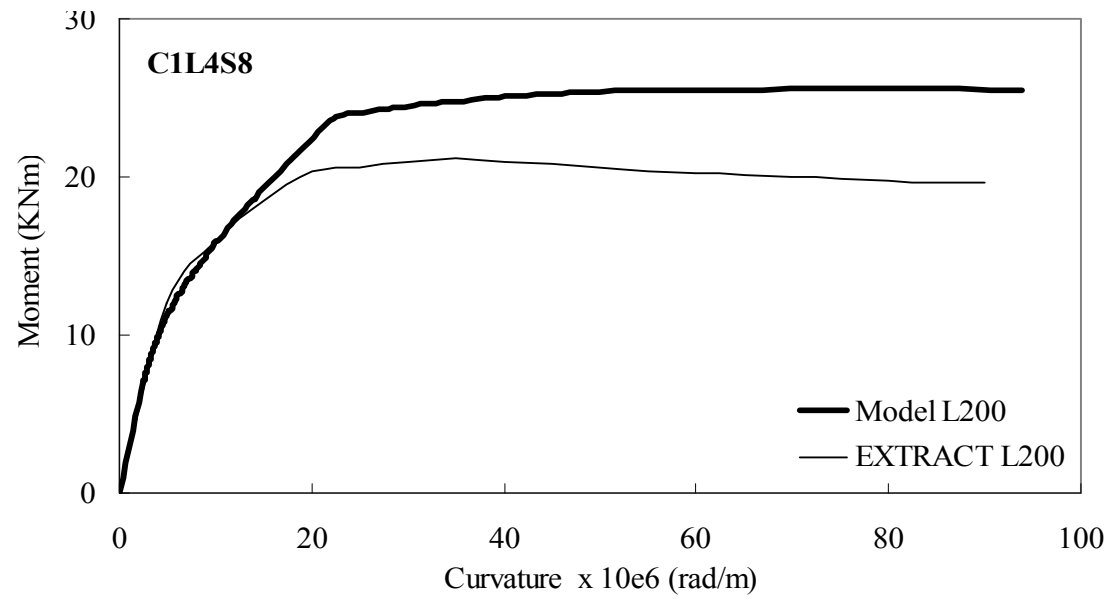

Figure 6: Output of EXTRACT program and the proposed model for moment-curvature diagrams for C1L4S8 at the axial load level of $200 \mathrm{kN}$. 
Figures 6-8 show the output of EXTRACT program [14] for C1L4S8 subjected to the axial load levels of $200 \mathrm{kN}, 400 \mathrm{kN}$ and $600 \mathrm{kN}$ respectively. EXTRACT program employs the Mander model for confined concrete. There are not significant differences if one compares the curvature values for both programs.

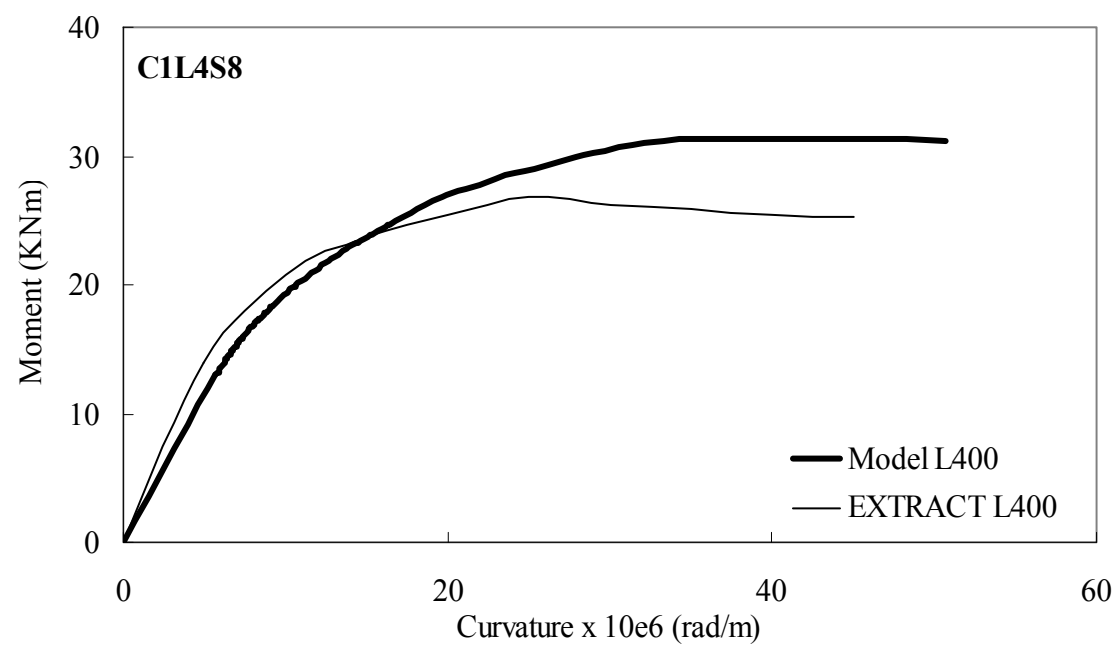

Figure 7: Output of EXTRACT program and the proposed model for moment-curvature diagrams for C1L4S8 at the axial load level of $400 \mathrm{kN}$.

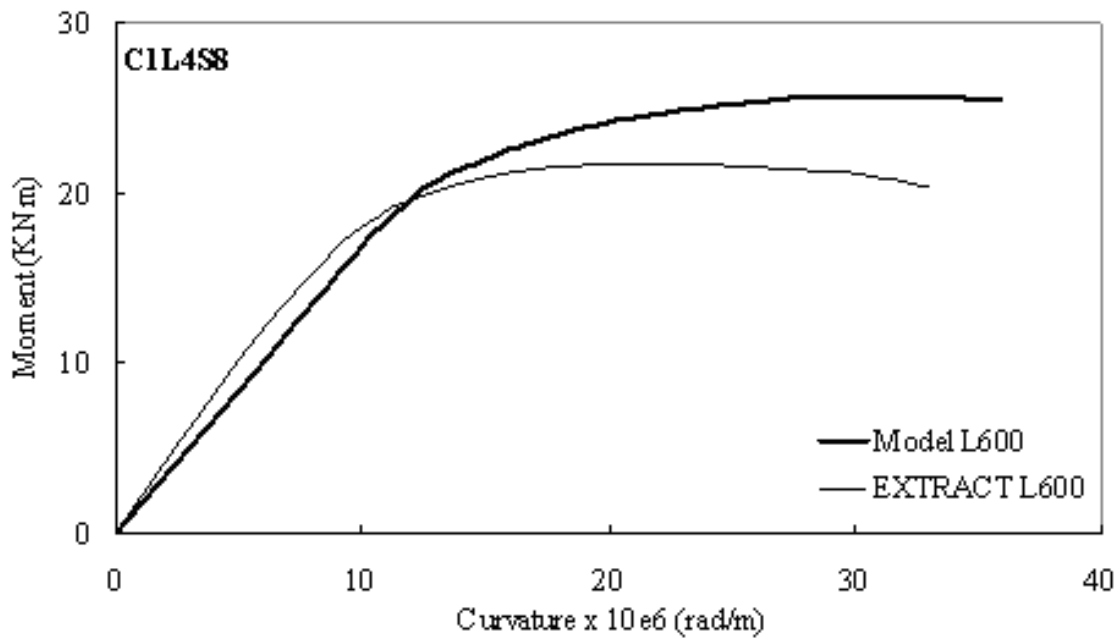

Figure 8: Output of EXTRACT program and the proposed model for moment-curvature diagrams for C1L4S8 at the axial load level of $600 \mathrm{kN}$. 


\section{Conclusion}

This paper has been primarily concerned with the modeling aspects for the axial behavior of RC columns. Experimental axial stress-strain curves of the four column specimens are predicted employing Koksal model. Furthermore, a spreadsheet-based program is constructed to produce moment-curvature plots for the performance-based design engineering approach. The following conclusions can be drawn based on the results of the analyses:

1. As can be seen in Figure 5, Koksal model successively predicts the axial behavior of the four RC column specimens tested under concentric loading.

2. It can be easily observed that Koksal model results into somewhat higher values for the moment carrying capacities than the outputs of EXTRACT program which employs Mander model in Figure 6-8, but the general trend of the curves are the same. The developed program gives $27 \mathrm{kNm}$ and $38 \mathrm{kNm}$ for moment carrying capacities at the axial load levels of $400 \mathrm{kN}$ and $600 \mathrm{kN}$ while EXTRACT program results are between $22 \mathrm{kNm}$ and $27 \mathrm{kNm}$.

\section{Acknowledgement}

The support of Boğaziçi University Research Fund (ref: research project 5232) for this paper is gratefully acknowledged.

\section{References}

[1] Richart, F.E., Bradtzaeg, A. and Brown, R. L. 1928. A study of the Failure of Concrete under Combined Compressive Stresses. Bulletin Np. 185, Engineering experimental station University of Illinois, Urbana, pp. 104.

[2] Hognestad, E., 1951. A Study of Combined Bending and Axial Load in Reinforced Concrete Members. Bulletin Series No.399, University of Illinois Eng. Exp. Station, Urbana.

[3] Kent, D.C. and Park, R. 1971. Flexural Members with Confined Concrete. Journal of the Structural Division, Proc. of the American Society of Civil Engineers, 97(ST7), pp.1969-1990.

[4] Sheikh, S.A. and Uzumeri, S.M. 1982. Analytical Model for Concrete Confinement in Tied Columns. Journal of the Structural Division, Proc. of the American Society of Civil Engineers, 108(ST12), pp. 2703-2722.

[5] Mander, J.B., Priestly, M.J.N. and Park, R. 1988. Theoretical Stress-Strain Model for Confined Concrete. Journal of the Structural Engineering, ASCE, 114(8), pp.1804-1826.

[6] Saatcioglu, M. and Razvi, S.R. 1992. Strength and Ductility of Confined Concrete. Journal of the Structural Engineering, ASCE, 118(6), pp.1590-1607. 
[7] Köksal, H.O. 2006. A Failure Criterion for RC Members Under Triaxial Compression. Structural Engineering and Mechanics, Techno-Press, 24(2), pp.137-154.

[8] Turgay, T. CFRP Uygulanmis betonarme elemanların performansı (The performance of FRP strengthened structural members). PhD thesis, Submitted to Yıldız Technical University; 2007.

[9] Köksal, H.O., Karakoç, C., Polat Z., Turgay T. and Akgün Ş. 2007.Evaluation of Experimental Procedures for Confined Concrete Columns. Computational Methods and Experimental Measurements XIII, WIT Transactions on Modeling and Simulation, 46, 233-242.

[10] Shrive, P.L., Azarnejad, A., Tadros, G., McWhinnie, C. and Shrive, N.G. 2003. Strength of Concrete Columns with Carbon Fibre Reinforcement Wrap. Canadian Journal of Civil Engineering, 30, pp. 543-554.

[11] Doran, B. 2009.Numerical simulation of conventional RC columns under concentric loading. Material and Design, 30(6), 2158-2166.

[12] Saenz, L.P. 1964. Discussion of Equation for Stress-Strain Curve of Concrete by Desai and Krishnan. ACI, 61(9), 1229-1235.

[13] Köksal, H.O, Doran, B., and Turgay, T. 2009. A practical approach for modeling FRP wrapped concrete columns. Constr. and Build. Mat., 23(3), $1429-1437$.

[14] EXTRACT-v.3.0.8, Cross section analysis program of structural engineers, TRC/Imbsen Software Systems. 